\title{
Niğde yöresinde patateste (Solanum tuberosum l.) sorun olan yabancı ot türlerinin yaygınlık ve yoğunluklarının belirlenmesi $^{1}$
}

\author{
Özgür Kıvılcım KILIC
}

\section{ABSTRACT \\ Determination of Weed Species, Distribution and Density in Potato Fields (Solanum tuberosum L.) in Niğde Province}

This study was carried out to determine the distribution and density of weed species which are problem on potato fields at around Niğde Province in 2016 year. Survey studies were made in potato cultivation field in Niğde center and its district (Altunhisar, Bor, Çamardı, Çiftlik, Ulukışla) between May and July on 180 potato fields. As a result of survey, 60 different weed species from 21 families were identified. The weed species with higher infestation rate and density according to average number of weeds $\mathrm{m}^{2}$ were found in this study as follows: Red pigweed (Amaranthus retroflexus L.,) with the density of 4.24 plants $/ \mathrm{m}^{2}$. Followed by $2.81 \mathrm{plants} / \mathrm{m}^{2}$ with white goosefoot (Chenopodium album L), 2.67 plants $/ \mathrm{m}^{2}$ with lying amaranth (Amaranthus hybridus L.), 1.46 plants $/ \mathrm{m}^{2}$ with black nightshade (Solanum nigrum L.), 1.45 plants $/ \mathrm{m}^{2}$ with white mustard (Sinapis arvensis L.), with field bindweed 1.45 plants $/ \mathrm{m}^{2}$ with field bindweed (Convolvulus arvensis L.), 1.32 plants $/ \mathrm{m}^{2}$ of barnyard grass (Echinochloa crus-galli). Weeds which are important in terms of frequency of occurrence is white goosefoot by $68 \%$, red pigweed by $65 \%$, field bindweed by $42 \%$, lying amaranth by $25 \%$, field mustard by $24 \%$, mat amaranth by $19 \%$, black nightshade by $15 \%$, Russian knapweed by $13 \%$, rough cocklebur by $12 \%$ were determined.

Keywords: Potato, Niğde, weeds, weed survey, weed density

\footnotetext{
${ }^{1} \mathrm{Bu}$ çalışma Ömer Halisdemir Üniversitesi Bilimsel Araştırma Projeleri Birimi tarafından FEB2014/31-BAGEP nolu proje ile desteklenmiştir.

2 Ömer Halisdemir Üniversitesi, Ayhan Şahenk Tarım Bilimleri ve Teknolojileri Fakültesi Bitkisel Üretim ve Teknolojileri Bölümü, Merkez Yerleşke, Bor Yolu Üzeri, 51240, Niğde

Sorumlu yazar (Corresponding author) e-mail: ozgur.kilinc@ ohu.edu.tr

Alınış (Received): 21.10.2016, Kabul ediliş (Accepted): 22.11.2016
} 


\section{ÖZ}

Bu çalışma, Niğde ili ve İlçeleri patates ekim alanlarında sorun olan yabancı ot türlerinin yoğunluklarını ve rastlanma sıklıklarını belirlemek amacıyla 2016 yılında yürütülmüştür. Sürvey çalışmaları Niğde Merkez ve İlçelerinde (Altunhisar, Bor, Çamardı, Çiftlik, Ulukışla) 180 tarlada Mayıs-Temmuz aylarında gerçekleştirilmiştir. Yapılan sürvey çalışması sonucunda, 21 farklı familyaya ait 60 farklı yabancı ot türü tespit edilmiştir. Survey yapılan tarlalardaki $\mathrm{m}^{2}$ 'deki yoğunluklara göre en fazla sorun olan tür $4,24 \mathrm{bitki} / \mathrm{m}^{2}$ yoğunluk ile Kırmızı köklü tilki kuyruğu (Amaranthus retroflexus L.) olmuştur. Bu türü 2,81 bitki $/ \mathrm{m}^{2}$ ile Sirken (Chenopodium album L.), 2,67 bitki/m² ile Melez horozibiği (A. hybridus L.), 1,46 bitki $/ \mathrm{m}^{2}$ ile Siyah it üzümü (Solanum nigrum L.), 1,45 bitki $/ \mathrm{m}^{2}$ ile Yabani hardal (Sinapis arvensis $\mathrm{L}$.), 1,45 bitki $/ \mathrm{m}^{2}$ ile Tarla sarmaşı ğ 1 (Convolvulus arvensis $\left.\mathrm{L}.\right)$ ve $1,32 \mathrm{bitki} / \mathrm{m}^{2}$ ile Darıcan [Echinochloa crus-galli (L.)] izlemiştir. Rastlanma sıklığına göre ise \%68 Sirken (C. album), \%65 Kırmızı köklü tilki kuyruğu (A. retroflexus), \%42 Tarla sarmaşı̆̆ı (C. arvensis), $\% 25$ Melez horozibiği (A. hybridus L.), \%24 Yabani hardal (S. arvensis), \%19 Yatık horoz ibiği (A. blitoides L.), \%15 Siyah it üzümü (S. nigrum ), \%13 Kekre (Acroptilon repens L.), \%12 Domuz pıtrağı (Xanthium strumarium L.) olarak belirlenmiştir.

Anahtar kelimeler: Patates, Niğde, yabanc1 otlar, survey, yabancı ot yoğunluğu

\section{GíRiş}

Anavatanı Güney Amerika olan ve And Dağları eteklerindeki arazilerde yerli halk tarafından yüzyıllardır doğal olarak yetiştirilen Solanaceae familyasına ait olan patates (Solanum tuberosum L.), 16. yüzyılın ikinci yarısında Amerika kıtasının keşfinden sonra İspanyollar tarafindan Avrupa'ya getirilmiştir (Brush 1980). İlk olarak İngiltere, İrlanda ve İskoçya ya, daha sonra diğer Avrupa ülkelerine yayıldığı bilinmektedir. Sömürgeleştirme ile Avrupa'dan diğer kıtalara yayılmıştır (Hawkes 1993). Kesin olmamakla birlikte Türkiye'ye ilk kez 19. yüzyıl sonlarında giren patates, önce Doğu Karadeniz Bölgesine, daha sonra da batıdan Trakya Bölgesine girmiş̧ir (Işık 1974, İlisulu 1986, Berksan 2002).

FAOSTAT, 2015 verilerine göre; dünyada yaklaşık olarak 20 milyon ha alanda patates üretilmektedir. En önemli patates üreticisi ülkeler Çin, Hindistan, Rusya, Ukrayna ve ABD`dir. Bu beş ülkenin dünya patates üretiminden aldıkları pay $\% 50$ yi aşmaktadır. Türkiye 2014 verilerine göre yaklaşık 1,5 milyon ha ekim alanı ve 4 milyon tonluk üretimi ile 19. sırada yer almaktadır (Anonim 2016a).

Patates üretimi Türkiye'de hemen hemen her ilde yapılmasına rağmen, yoğun olarak sırasıyla Niğde, İzmir, Konya, Afyon ve Kayseri illerinde gerçekleştirilmekte; bu illeri sırasıyla Bolu, Adana, Nevşehir, Aksaray, Bitlis izlemektedir. Toplam patates üretiminin yaklaşık \%75 i bu illerde yapılmaktadır (Anonim 2016b). Toprak yapısı ve iklim şartlarının patates üretimi için uygun olmasından dolayı Niğde'de uzun yıllardır patates üretimi yapılmaktadır. Niğde patates ekim alanı ve üretim miktarı açısından ülkemizde ilk sırada yer almaktadır. 2014 verilerine göre Niğde yaklaşık 180.000 da patates ekim alanı ve 728000 tonluk patates üretimi ile Türkiye'deki patates üretiminde \%13'lük paya sahip iken, 2015'de ekim alanı 155.000 da, üretim 
miktarı ise 510.000 ton'a gerilemiştir. Hektara verim $33.400 \mathrm{~kg}$ seviyesindedir. Niğde'de toplam sulanan tarım arazilerinin yaklaşı $\% 20$ 'sinde patates üretimi yapılmakta olup toplam 81 köyde (toplam köylerin \%51'i) 5093 çiftçinin (toplam çiftçilerin \%35'i) geçim kaynağı durumundadır (Çalışkan ve ark. 2010, Aksoy ve ark. 2014).

Patates içerdiği karbonhidrat, protein, nişasta ve vitaminler itibariyle aranan bir besin kaynağıdır. Dünya nüfusunun beslenmesinde pirinç, buğday ve mısırdan sonra dördüncü sırada yer alan patates, sanayi hammaddesi olarak da önemli bir üründür. Patates yumrusunun 3/4 ünden fazlası sudur. Kuru maddesinin ise ortalama \%75'i nişastadır. Patatesten elde edilen nişasta ve nişasta ürünleri gıda, tekstil, kâğıt, ilaç sanayi ve zamk imali gibi farklı yerlerde değerlendirilmektedir (Arslan ve ark. 2002). Patates üretiminde hedeflenen verime ulaşabilmek için hastalık, zararlı ve yabancı otlar ile mücadele büyük önem arz etmektedir (Bilgili ve Kadığlu 2003). Yabanc1 otlar diğer kültür bitkilerinde olduğu gibi, patates alanlarında da önemli verim kayıplarına neden olmaktadır. Yabancı ot rekabeti nedeniyle patates yumru büyüklüğü, ağırlığı ve verim miktarı azalmaktadır. Ayrıca yabancı otlar hasadı zorlaştırarak, hastalık ve zararlılara konukçuluk ederek dolaylı olarak zararlı olmaktadırlar (Zengin ve Güncan 1993).

Yabancı otlarla mücadele yönteminin tayininde ilk adım sorun olan bu otların doğru tür teşhislerinin yapılmasıdır. Her yabancı otun mekanik, kimyasal mücadelesinde farklı yöntemlere ihtiyaç duyulabilir. Yabancı otları tanımadan yapılacak mücadele başarısız olmakta, hem zaman hem de maddi kayıplara neden olmaktadır. Bunun yanında çevre kirlenmesine yol açarak ekolojik dengeye zarar vermektedir. Yabancı otların mücadele yöntemlerine karşı en hassas olduğu dönem erken gelişim dönemidir. Bu nedenle yabancı otları erken gelişim devrelerinde tanımak, mücadele yönteminin seçiminde yardımcı olacaktır (Carey ve ark. 1993).

\section{MATERYAL VE METOT}

$\mathrm{Bu}$ çalışma; Niğde merkez ve ilçelerinde patates ekim alanlarında bulunan yabancı ot türlerinin belirlenmesi amacıyla 2016 yılı vejetasyon döneminde dikimden sonra mayıs-temmuz aylarında yürütülmüştür. Patates ekim zamanının ilçelerde farklılık göstermesinden dolayı sürvey çalışmaları sırasıyla Altunhisar, Niğde merkez, Bor, Ulukışla, Çiftlik ve Çamardı ilçelerinde gerçekleştirilmiştir (Şekil 1). Çizelge 1'de görüleceği üzere çalışmanın yürütüldüğü ilçelerde farklı yoğunlukta patates üretimi yapılmaktadır. Sürvey alanları Niğde Tarım İl Müdürlüğü'nden alınan verilere göre belirlenmiş̧ir. Sürvey Niğde ili ve yöresi patates ekim alanlarının tamamını temsil edecek şekilde bölümlü örnekleme yöntemine göre oransal olarak ilçelere dağıtılan toplam 180 tarlada yapılmıştır (Bora ve Karaca 1970, Bilgili ve Kadığlu 2003). Sürvey yapılan tarlalar arasında en az $3 \mathrm{~km}$ uzaklık olmasına özen gösterilmiştir. Sürvey yapılırken tarla büyüklüğü $10-20$ da ise 5, 20 da'dan büyük ise en az 10 çerçeve atılarak yabancı otlar belirlenmiştir. Sayımlarda $1 \mathrm{~m}^{2}$ 'lik çerçeve kullanılmış, kenar tesirini ortadan kaldırmak için sayımlar tarla sınırının en az 15 m 
Niğde Yöresinde Patateste (Solanum tuberosum L.) Sorun Olan Yabancı Ot Türlerinin Yaygınlık ve Yoğunluklarının Belirlenmesi

içinden yapılmıştır. Yabancı ot türlerinin rastlanma sıklıkları ve yoğunlukları her tür için Odum (1971)'a göre hesaplanmıștır. Bitki yoğunluğu (bitki $/ \mathrm{m}^{2}$ ) sayım noktasında yapılan sürveylerdeki toplam $\mathrm{m}^{2}$ 'deki bitki sayısının toplam sürvey adedine bölünmesiyle hesaplanmıştır. Rastlanma sıklığı bir türün rastlandığı çerçeve sayısının atılan toplam çerçeve sayısına oranıdır (Odum 1971).

Çizelge 1: Niğde merkez ve ilçelerinde 2016 yılında patates üretim alanları ve örnekleme sayıları

\begin{tabular}{|l|c|c|c|}
\hline $\begin{array}{l}\text { Sürvey } \\
\text { Bölgeleri }\end{array}$ & $\begin{array}{c}\text { Bölge Rakımı } \\
(\mathbf{m})\end{array}$ & $\begin{array}{c}\text { Toplam ekilen Alan } \\
(\mathbf{d a})\end{array}$ & $\begin{array}{c}\text { Örnekleme } \\
\text { Sayısı }\end{array}$ \\
\hline Niğde Merkez & 1.230 & 202.830 & 80 \\
\hline Altunhisar & 1.050 & 8.250 & 20 \\
\hline Bor & 1.100 & 7500 & 20 \\
\hline Çamardı & 1.600 & 2580 & 15 \\
\hline Çiftlik & 1.555 & 37500 & 35 \\
\hline Ulukışla & 1.427 & 790 & 10 \\
\hline Toplam & & 259.450 & 180 \\
\hline
\end{tabular}

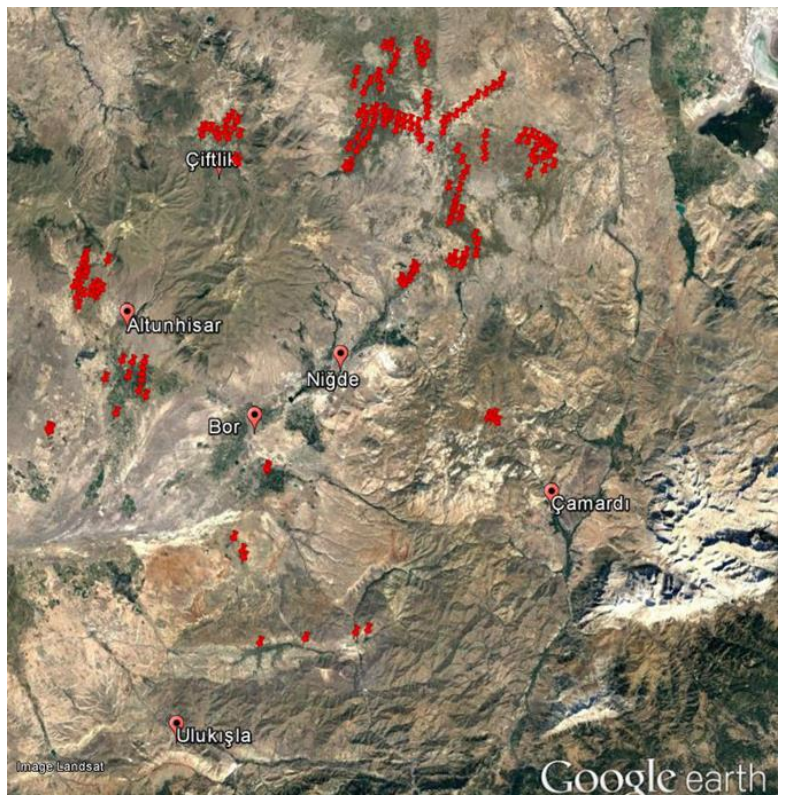

Şekil 1. Niğde ili patates ekim alanlarında sürvey yapılan alanın uydu görüntüsü ve survey noktalar1

Toplanan bitkilerin teşhisi Flora of Turkey (Davis 1965-1989) adlı eserden yararlanılarak yapılmıştır. Bazı türlerin teşhisi, Niğde Üniversitesi ve Süleyman Demirel Üniversitesi, Fen Edebiyat Fakültesi, Biyoloji Bölümlerinde yaptırılmıştır. Yabancı otların Türkçe isimleri Özer ve ark. (1999) ve Baytop (1994)'dan yararlanılarak verilmiştir. 


\section{SONUÇLAR}

Niğde ili patates dikim alanlarında bulunan yabancı otların ve yoğunluklarının saptanması amaciyla 2016 yılı vejetasyon döneminde dikimden sonra yapılan survey çalışmaları sonucu, 21 farklı familyaya ait 13'ü monokotiledon, 47'si dikotiledon olmak üzere 60 yabancı ot türü tespit edilmiştir (Çizelge 2).

Saptanan yabanc1 ot türleri ait oldukları familyalara göre değerlendirildiğinde; Poaceae familyası 13 tür ile ilk sırayı alırken, bu familyayı 10 tür ile Asteraceae, 5 tür ile Brassicaceae, 4 tür ile Fabaceae, 3'er tür ile Chenopodiaceae, Amaranthaceae ve Boraginaceae familyaları takip etmektedir. Önemli bulunan familyalar saptanan 60 türün \% 68,3’ünü oluşturmaktadır (Şekil 2).

Survey yapılan tarlalardaki $\mathrm{m}^{2}$ deki yoğunluklarına göre en fazla sorun olarak karşımıza çıkan tür 4.24 bitki $/ \mathrm{m}^{2}$ yoğunluk ile Kırmızı köklü tilki kuyruğu (Amaranthus retroflexus L.) olmuştur. $\mathrm{Bu}$ türü $2.81 \mathrm{bitki} / \mathrm{m}^{2}$ ile Sirken (Chenopodium album L.), 2.67 bitki $/ \mathrm{m}^{2}$ ile Melez horozibiği (Amaranthus hybridus L.), 1.46 bitki $/ \mathrm{m}^{2}$ ile Siyah it üzümü (Solanum nigrum L.), 1.45 bitki $/ \mathrm{m}^{2}$ ile Yabani hardal (Sinapis arvensis L.) $1.45 \mathrm{bitki} / \mathrm{m}^{2}$ ile Tarla sarmaşı̆̆ (Convolvulus arvensis L.) ve 1.32 bitki $/ \mathrm{m}^{2}$ ile Darıcan (Echinochloa crus-galli), 0.98 bitki $/ \mathrm{m}^{2}$ ile Melez horozibiği (Amaranthus hybridus L.), 0,75 bitki $/ \mathrm{m}^{2}$ ile Domuz pitrağ 1 (Xanthium strumarium L.) ve 0,75 bitki $/ \mathrm{m}^{2}$ ile Köpek dişi ayrığı (Cynadon dactylon L. Pers.) izlemiştir.

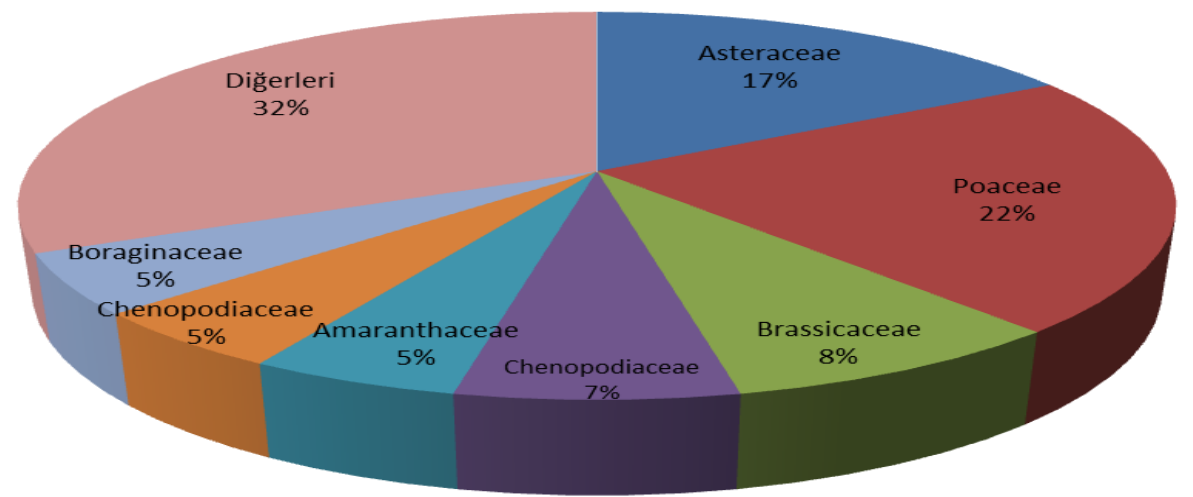

Şekil 2. Niğde patates ekim alanlarında tespit edilen yabancı otların familyalara göre değerlendirilmesi

Niğde yöresi patates ekim alanlarında bulunan yabancı ot türleri rastlama sıklığı ilçelere göre çok farklılık göstermektedir. Toplam survey alanlarının ortalaması dikkate alınarak rastlanma sıklığı değerlendirildiğinde; \%68 Sirken (C. album), \%65 Kırmızı köklü tilki kuyruğu (A. retroflexus L.), \%42 Tarla sarmaşı̆̆ (C. arvensis L.), \%25 Melez horozibiği (A. hybridus ), \%24 Yabani hardal (Sinapis arvensis L. ), \%19 Yatık horoz ibiği (Amaranthus blitoides L.), \%15 Siyah it üzümü (Solanum nigrum 
Niğde Yöresinde Patateste (Solanum tuberosum L.) Sorun Olan Yabancı Ot Türlerinin Yaygınlık ve Yoğunluklarının Belirlenmesi

L.), \%13 Tarla eşek marulu (Sonchus arvensis L.), \%13 kekre (Acroptilon repens

L.), \%12 Domuz pitrağı (Xanthium strumarium L.), \%11 Köy göçüren (Cirsium arvense (L.) Scop), \%10 Darıcan (E. crus-galli L.) ve Karakavuk (Chondrilla juncea L.) olarak belirlenmiş diğer türlerin rastlanma sıklıkları Çizelge 2'de görüleceği gibi \%10'un altında kalmaktadır.

Çizelge 2. Niğde yöresi Patates (Solanum nigrum L.) Ekim alanlarında tespit edilen yabancı otlar, yoğunlukları (bitki $/ \mathrm{m}^{2}$ ) ve rastlanma sıklıkları (\%)

\begin{tabular}{|c|c|c|c|c|}
\hline Familya & Latince Adı & Türkçe Adı & $\begin{array}{l}\text { Rastlanma } \\
\text { sıklığı }(\%)\end{array}$ & $\begin{array}{l}\text { Yoğunluk } \\
(\text { bitki//m²) }\end{array}$ \\
\hline \multirow{3}{*}{ Amaranthaceae } & Amaranthus retroflexus $L$. & $\begin{array}{l}\text { Kırmızı köklü } \\
\text { tilki kuyruğu }\end{array}$ & 65 & 4,24 \\
\hline & Amaranthus blitoides L. & Yatık horozibiği & 19 & 0,98 \\
\hline & Amaranthus hybridus L. & Melez horozibiği & 25 & 2,67 \\
\hline Apiaceae & Bifora radians $L$. & Kokarot & 2 & 0,01 \\
\hline \multirow{10}{*}{ Asteraceae } & Acroptilon repens $($ L.) & Kekre & 13 & 0,23 \\
\hline & Anthemis arvensis $L$. & $\begin{array}{ll}\begin{array}{l}\text { Tarla köpek } \\
\text { papatyas1 }\end{array} & \\
\end{array}$ & 2,3 & 0,02 \\
\hline & Centaurea depressa $L$. & Gökbaş & 7 & 0,03 \\
\hline & Chondrilla juncea $L$. & Karakavuk & 10 & 0,04 \\
\hline & Cirsium arvense (L.) Scop & Köy göçüren & 11 & 0,19 \\
\hline & Lactuca serriola $L$. & $\begin{array}{l}\text { Dikenli yabani } \\
\text { marul }\end{array}$ & 9 & 0,02 \\
\hline & Matricaria perforata Merat. & Kokusuz papatya & 2 & 0,04 \\
\hline & Sonchus arvensis $L$. & Tarla eşek marulu & 13 & 0,04 \\
\hline & Taraxacum officinale Web. & Karahindiba & 1 & 0,02 \\
\hline & Xanthium strumarium L. & Domuz Pitrağ 1 & 10 & 0,75 \\
\hline \multirow{3}{*}{ Boraginaceae } & Anchusa officinalis L. & Siğırdili & 2 & 0,01 \\
\hline & Heliotropium europaeum L. & Beyaz bambul & 3 & 0,03 \\
\hline & Myosotis arvensis L. Hill & Dağ minesi & 1 & 0,32 \\
\hline \multirow{5}{*}{ Brassicaceae } & Brassica nigra (L.) Koch & Siyah hardal & 1 & 0,01 \\
\hline & Cardaria draba (L.) Desv & Yabani tere & 0,4 & 0,02 \\
\hline & Erysimum cheirantoides $L$. & Zarife otu & 0,5 & 0,01 \\
\hline & Raphanus raphanistrum L. & Yabani turp & 0,3 & 0,01 \\
\hline & Sinapis arvensis $L$. & Yabani hardal & 24 & 1,46 \\
\hline \multirow{3}{*}{ Chenopodiaceae } & Chenopodium album L. & Sirken & 68 & 2,81 \\
\hline & Chenopodium botrys $L$. & Kizılbacak & 4 & 0,16 \\
\hline & Salsola ruthenica İljin & Keteğen & 8 & 0,28 \\
\hline Convolvulaceae & Convolvulus arvensis $L$. & Tarla sarmaşı $\breve{g}_{1}$ & 42 & 1,45 \\
\hline Cuscutaceae & Cuscuta spp. & Küsküt & 2 & 0,34 \\
\hline Euphorbiaceae & Euphorbia spp. & Sütleğen & 3 & 0,01 \\
\hline \multirow{4}{*}{ Fabaceae } & Alhagi pseudalhagi $L$. & Devedikeni & 6 & 0,06 \\
\hline & Lathyrus tuberosus $L$ & Mürdümük & 0,34 & 0,01 \\
\hline & $\begin{array}{l}\text { Melilotus officinalis (L.) } \\
\text { Desr. }\end{array}$ & Kokulu sariyonca & 1,53 & 0,01 \\
\hline & Vicia cracca L. & Kuş fiği & 0,56 & 0,02 \\
\hline \multirow[t]{2}{*}{ Lamiaceae } & Ajuga reptans $L$. & $\begin{array}{l}\text { Sürünücü } \\
\text { mayasilotu }\end{array}$ & 0,1 & 0,02 \\
\hline & Lamium amplexicaule. $L$. & Ballibaba & 0,5 & 0,05 \\
\hline Malvaceae & Malva neglacta Wallr. & Ebegümeci & 3 & 0,01 \\
\hline
\end{tabular}


Kılıç K. Ö., Bitki Koruma Bülteni, 56 (4), 2016

\begin{tabular}{|c|c|c|c|c|}
\hline & Malva sylvestris $L$. & Büyük ebegümeci & 2 & 0,01 \\
\hline Orabanchaceae & Orabanche ramosa $L$. & Canavar otu & 2 & 0,61 \\
\hline \multirow{2}{*}{ Papaveraceae } & Fumaria officinalis $L$. & Hakiki şehtare & 5,2 & 0,45 \\
\hline & Papaver rhoeas $L$. & Gelincik & 6,3 & 0,13 \\
\hline \multirow{13}{*}{ Poaceae } & Agropyron repens (L.) & Ayrik otu & 2,3 & 0,31 \\
\hline & $\begin{array}{l}\text { Alopecurus myosuroides } \\
\text { Huds. }\end{array}$ & Tilkikuyruğu & 1,7 & 0,13 \\
\hline & Avena sativa $L$. & Yabani yulaf & 1,4 & 0,24 \\
\hline & Bromus tectorum & Püsküllü çayır & 1,2 & 0,25 \\
\hline & Cynadon dactylon (L.) Pers & Köpek dişi ayrığ1 & 7,4 & 0,75 \\
\hline & Dactylis glomerata $L$. & Domuz ayrı̆g 1 & 3,4 & 0,63 \\
\hline & $\begin{array}{l}\text { Digitaria sanguinalis (L.) } \\
\text { Scop }\end{array}$ & Çatal otu & 8 & 0,32 \\
\hline & Echinochloa crus-galli & Darican & 10 & 1,32 \\
\hline & Phalaris canariensis $L$. & $\begin{array}{l}\text { Uzun başaklı kuş } \\
\text { yemi. }\end{array}$ & 0,26 & 0,96 \\
\hline & Phragmites australis L. & Kamış & 0,4 & 0,01 \\
\hline & Poa spp. & Salkım otu & 0,7 & 0,46 \\
\hline & Setaria glauca (L.) P.B. & Sarı tüylü darı & 1,42 & 0,04 \\
\hline & Sorhum halepense (L.) Pers. & Kanyaş & 0,8 & 0,05 \\
\hline Polygonaceae & Polygonum aviculare $L$. & $\begin{array}{l}\text { Kuş } \\
\text { çobandeğneği }\end{array}$ & 8,9 & 0,09 \\
\hline Portulacaceae & Portulaca oleracea $L$. & Semiz otu & 6,4 & 0,37 \\
\hline \multirow[b]{2}{*}{ Ranunculaceae } & Consolida regalis S.F. Gray & Çatal mahmuz otu & 0,9 & 0,04 \\
\hline & Ranunculus arvensis $L$. & $\begin{array}{l}\text { Tarla düğün } \\
\text { çiçeği }\end{array}$ & 0,89 & 0,07 \\
\hline \multirow{2}{*}{ Rosaceae } & Aphanes arvensis $L$. & Terspençe & 0,1 & 0,01 \\
\hline & Potentilla reptans $L$. & Reşatınotu & 0,1 & 0,02 \\
\hline Rubiaceae & Galium aperina $L$. & Dil kanatan & 2 & 0,41 \\
\hline \multirow{2}{*}{ Solanaceae } & Datura stramonium L. & Şeytan elmas1 & 7 & 0,35 \\
\hline & Solanum nigrum $L$. & Siyah itüzümü & 15 & 1,46 \\
\hline
\end{tabular}

Sürvey çalışmaları sonucu Niğde yöresindeki yabancı otların yoğunluk ve rastlanma sıklıkları ilçeler bazında incelendiğinde farklılıklar gösterdiği tespit edilmiştir. Bazı yabancı otlar bazı ilçelerde yoğun iken diğer ilçelerde tespit edilememiştir. Sürvey çalışmalarından elde edilen sonuçlar ilçe bazında değerlendirilecek olursa;

Niğde Merkez İlçe: 202.830 da alanda özellikle Niğde il merkezinin kuzeyinde yer alan Misli ovasında yoğun bir patates ekimi yapılan merkez ilçede 21 farklı familyadan 53 yabancı ot türü tespit edilmiştir. Yabancı ot yoğunluğu 1 ile 186 bitki arasında değişmektedir. Ortalama yoğunluk $37.45 \mathrm{bitki} / \mathrm{m}^{2}$ olarak tespit edilmiştir. Merkez ilçede yoğun olarak tespit edilen yabancı otlar Amaranthus hybridus L., Chenopodium album L., A. retroflexus L., Solanum nigrum L., P. aviculare L., C. arvensis L., Salsola ruthenica L., Myosotis arvensis L. ve Heliotropium europaeum L. olduğu saptanmıştır. Bunula birlikte lokal olmakla birlikte bazı tarlalarda parazit bir yabancı ot olan canavar otu (Orabanche spp.) yoğunluğunun $157 \mathrm{bitki} / \mathrm{m}^{2}$ ye ulaştığı tespit edilmiştir. Daha önce yapılan çalışmalarda (Üstüner ve Güncan, 2002) orta yoğunlukta tespit edilen Cuscuta spp. ve Orabanche spp. yaygınlığ özellikle bu ilçe sınırlarındaki patates ekim alanlarında her geçen yıl arttığı gözlemlenmiştir. 
Niğde Yöresinde Patateste (Solanum tuberosum L.) Sorun Olan Yabancı Ot Türlerinin Yaygınlık ve Yoğunluklarının Belirlenmesi

Altunhisar İlçesi: Niğde il merkezinin güneyinde yer alan Altunhisar ilçesinde 8.250 da alanda yoğun patates ekimi yapılmaktadır. Bu ilçede merkez ilçede olduğu gibi uzun yıllardır patates tarımı yapılmaktadır. Sürvey çalışmaları sonucu 21 farklı familyadan 48 farklı yabanc1 ot türü tespit edilmiştir. Yabanc1 ot yoğunluğunun 1$178 \mathrm{bitki} / \mathrm{m}^{2}$ olarak değişkenlik gösterdiği ortalama yoğunluğun $43,6 \mathrm{bitki} / \mathrm{m}^{2}$ olduğu belirlenmiştir. Merkez ilçede olduğu gibi Chenopodium album L., ve Amaranthus retroflexus L., C. arvensis L., Salsola ruthenica L., P. olearecea L., Solanum nigrum L. A. myosurides L., Datura stramonium L. ve Steria glauca en yoğun olarak tespit edilen yabancı otlardır. İlçede Siyah it üzümü (Solanum nigrum L.) yoğunluğunun bazı tarlalarda 75 bitki $/ \mathrm{m}^{2}$ seviyesine ulaştı̆̆ ve entegre mücadelede ciddi sorunlar yaşandığ tespit edilmiştir.

Çiftlik İlçesi: Melendiz Ovasının bulunduğu Çiftlik ilçesi, Merkez ilçeden sonra 37.500 da ekim alanı ile il genelinde ikinci sırada yer almaktadır. Bu ilçede 42 farklı yabanc1 ot türüne rastlanmıştır. Yabancı ot yoğunluğu 1-124 bitki $/ \mathrm{m}^{2}$ olarak değişmekte ve ortalama yoğunluk $18.53 \mathrm{bitki} / \mathrm{m}^{2}$ olarak tespit edilmiştir. Bu ilçede yoğunluğu en fazla olan yabanc1 otlar $A$. blitoides L., C. album L., A. retroflexus L., $P$. aviculare A. hybridus L., S. arvensis $\mathrm{L}$. ve $C$. arvensis $\mathrm{L}$. olarak belirlenmiştir. $\mathrm{Bu}$ ilçede patates tarlalarındaki yabancı ot topluluğunun esas üyesi Amaranthus türleridir.

Çamardı İlçesi: 2580 da alanda patates yetiştirilen bu ilçede 25 farklı ot türü tespit edilmiştir. Yabanc1 ot yoğunluğu 1-78 bitki $/ \mathrm{m}^{2}$ ve ortalama yoğunluk $13.32 \mathrm{bitki} / \mathrm{m}^{2}$ olarak belirlenmiştir. Bu yörede Bromus tectorum L., Chenopodium album L., Amaranthus retroflexus, X. strumarium Chondrilla juncea L., A. retroflexus ve Polygonum aviculare L. yoğun olarak saptanmıştır.

Ulukışla ilçesi: 790 da gibi sınırlı bir alanda patates tarımı yapılan ilçede 36 farklı yabanc1 ot türü tespit edilmiştir. Yabancı ot yoğunluğu 1 ile 76 bitki $/ \mathrm{m}^{2}$ arasında değişmekte ve ortalama yoğunluk $25.66 \mathrm{bitki} / \mathrm{m}^{2}$ olarak tespit edilmiştir. Bu ilçede yoğunluğu en fazla olan yabancı otlar sirasıyla A. retroflexus L., C. album L., Sinapis arvensis L., A. blitoides, Convolvulus arvensis L., Cirsium arvense, Polyugonum aviculare ve $X$. strumarium olarak tespit edilmiştir.

Bor İlçesi: 7500 alanda patates üretimi yapılan ilçede patates tarım alanlarının yaklaşık yarısı (3000 da) Çukurkuyu kasabası sınırlarında bulunmaktadır ve son birkaç yıldır patates ekimi yapılmaktadır. Bu alanlarda yabancı ot yoğunluğunun oldukça düşük olduğu tespit ediliştir. Ancak Balcı, Kemerhisar ve Tepeköy köylerinde uzun yıllardır patates dikimi yapıldığı için bu köylerdeki yabancı ot yoğunluğunun yüksek olduğu görülmüştür. Bu ilçede patates dikim alanlarında 40 farklı yabancı ot türü tespit edilmiştir. Yabancı ot yoğunluğu $17.06 \mathrm{bitki} / \mathrm{m}^{2}$ olarak tespit edilmiştir. Bu ilçede yoğunluğu en fazla olan yabancı otlar sırasıyla $C$. album L. , A. retroflexus L., Sinapis arvensis L., Portulaca olearecea ve X. strumarium olarak tespit edilmiştir. 


\section{TARTISMA VE KANI}

Tarım alanlarında bulunan yabancı otlar ile mücadele her geçen gün daha çok önem kazanmakta olup, entegre mücadeleyi zorunlu kılmaktadır. Entegre mücadelenin uygun bir şekilde yapılması için; yabancı otların türleri, biyolojisi, zarar seviyeleri ve rekabet yeteneklerinin belirlenmesi gerekmektedir (Akça ve Işık 2016). Bu çalışmada; Niğde ili ve ilçelerinde patates dikim alanlarında bulunan yabancı otların tespiti yapılmıştır. $\mathrm{Bu}$ amaçla yapılan surveyler sonucunda 21 farklı familyaya ait 60 yabanc1 ot türü saptanmıştır. Tespit edilen bu yabanc1 ot türlerinden 13'ü monokotiledon, 47'i dikotiledondur. Survey sonuçlarına göre en çok sorun olan yabanc1 otlar; A. retroflexus L., A. hybridus L., A. blitoides L., C. album L., S. arvensis L., C. arvensis L., S. nigrum L. olarak bulunmuştur. Yabanc1 otların yoğunlukları ilçelere göre farklılık arz etmektedir. Yabancı otların yoğunluk ve rastlanma sıklıkları bazı ilçelerde çok yüksek iken bazı ilçelerde çok düşük seviyededir. Bu durumun ilçelerin farklı ekolojilere (rakım, toprak yapısı, yağış miktarı) sahip olmalarından ve patates yetiştiriciliğindeki farklı uygulamalardan kaynaklandığ 1 tahmin edilmektedir. Amaranthus retroflexus, C. album, S. arvensis 'e bütün ilçelerde rastlanmış, S. nigrum, D. stramonium, Cuscuta spp., Orabanche spp. bazı ilçelerde daha çok lokal alanlarda yoğun olarak tespit edilmiş, bazı ilçelerde ise hiç bulunamamıştır. Bunun nedeninin, Niğde ve ilçelerinde rakımın, toprak yapısının ve patates yetiştiriciliğinin ilçelere göre farklılık göstermesinden kaynaklanabileceği düşünülmektedir. Survey yapılan Niğde ve ilçelerinde rakım 1000 ile 1600 m arasında değişmektedir. Bunun yanı sıra toprak yapısı ve yıllık yağış miktarı ilçelere göre oldukça değişkendir. Patates yetiştiriciliğinde ilçeler arasında kültürel yöntemler, herbisit kullanımı ve münavebe uygulaması farklılık göstermektedir. Son yıllarda bölgede hayvancılı̆̆ın gelişmesiyle geniş ekim alanları bulan yoncada yaygın şekilde görülen parazit bir yabanc1 ot olan Cuscuta approximata Bab., (Küçük tohumlu yonca küskütü)'nın özellikle merkez ilçe sınırlarındaki patates üretim alanlarında lokal tarlalarda ciddi verim kayılarına neden olduğu belirlenmiştir. Bölgede ciddi sorun olmaya başlayan ve mücadelesinde sıkıntılar yaşanan diğer önemli yabancı ot Canavar otu türleri (Orabanche spp.)'dir. Orabanche spp. özellikle Merkez ve Altunhisar ilçelerinde lokal bazı tarlalarda 120 bitki/m² gibi yüksek oranda bulunmuştur. Üstüner ve Güncan (2002)'ın Niğde ili ve yöresindeki patates tarlalarında yapmış olduğu sürvey çalışmalarında 29 familyaya ait 94 farklı yabancı ot türü tespit etmişlerdir. Tespit ettikleri en yoğun türler sırasıyla A. retroflexus L. (Kırmızı köklü tilki kuyruğu), Chenopodium album L. (Ak kazayağı), Polygonum aviculare L. (Çoban değneği), Convolvulus arvensis L. (Tarla sarmaşığı) ve Setaria glauca (L.) P.B. (Sarı tüylü darı) bulunmaktadır. Her iki survey çalışması bazı noktalarda benzerlik bazı noktalarda ise farklılık göstermektedir. Bu çalışma ile Niğde yöresi patates ekim alanlarında yukarıdaki çalışmaya göre daha az yabancı ot türüne rastlanmıştır. Ancak yaptığımız surveylerde daha önceki çalışmaya göre, $\mathrm{m}^{2}$ ' deki yoğunlukları düşük olan ve rastlanma sıklıkları önemli derecede artan bazı yabanc1 ot türleri A. hybridus, S. nigrum, Orabanche spp., Cuscuta spp. ve $X$. strumarium olarak tespit edilmiştir. Yapılan kültürel işlemler, toprak işleme 
Niğde Yöresinde Patateste (Solanum tuberosum L.) Sorun Olan Yabancı Ot Türlerinin Yaygınlık ve Yoğunluklarının Belirlenmesi

teknikleri, toprağın işleme sıklığı, kullanılan tohumluk, ilaçlama, gübreleme, münavebe, ürün deseni gibi 2000'li y1llardan günümüze değişen oldukça farklı faktörlerden kaynaklanabileceği muhtemeldir. Diğer bir faktör ise; bölgede uzun yıllar boyunca yoğun patates üretimi yapılan Merkez ilçe, Altunhisar ve Çiftlik ilçelerinde uygulanan yanlış üretim metotları, aynı etki mekanizmasına sahip herbisitlerin devamlı kullanımı, buna bağlı olarak bazı yabancı otlarda ortaya çıan seçicilik ve direnç mekanizmalarındaki değişimlerden kaynaklandığı düşünülebilir. Farklı zamanlarda değişik bölgelerde yapılan survey çalışmaları arasındaki farklı sonuçlar, survey alanının değişik iklim ve toprak karakterine sahip olmasından ileri gelmektedir. Zengin ve Güncan (1993), Erzurum ve yöresi patates dikim alanlarında yaptıkları survey çalışmalarında 114 yabancı ot türü belirlemiş̧ler ve en önemli 6 yabanc1 ot türünün $A$. retroflexus, $C$. album, $S$. viridis, $C$. arvense, E. ramossissimum ve $C$. anomalum olarak bildirmişlerdir. Bolu patates dikim alanlarında 14 familyaya ait toplam 15 yabancı of türü saptanmıştır (Sönmez 1976). Tokat yöresi patates dikim alanlarında yapılan çalışmalarda yabancı ot türü 60 olarak belirlenmiştir (Bilgili ve Kadıŏlu, 2003). Farklı zamanlarda farklı ülke ve bölgelerde yapılan survey çalışmalarında benzer sonuçlar elde edilmiştir. Colorado patates tarlalarının en yaygın türü A. retroflexus'tur (Zimdahl 1976). Yine ABD'nin farklı eyaletlerinde yapılan farklı çalışmalarda patates tarlalarında en yaygın yabancı otlar $C$. album ve A. retroflexus olarak tespit edilmiştir (Eberlein ve ark. 1997, Gallandt ve ark. 1998). Türkiye'nin farklı bölgelerinde yapılan survey çalışmalarında tespit edilen yabancı ot türlerinin büyük kısmı Niğde ve yöresi patates dikim alanlarında da saptanmıştır. Yaptığımız çalışmanın sonuçları; Ege, Marmara ve Doğu Anadolu bölgelerinde Sakarya, Bolu ve Erzurum illerinde değişik zamanlarda farklı araştırmacılar tarafından yapılan surveylerden elde edilen sonuçlara benzerlik göstermektedir (Sönmez 1976, Özer 1977,Zengin ve Güncan, 1993, Kırsoy ve Nemli 2001). Ayrıca Polonya ve ABD'nin Virginya eyaletinde yapılan sürvey çalışmalarında da benzer bulgular elde edilmiştir (Kubat ve ark. 1996).

Bir üretim alanında uzun yıllar boyunca aynı etki mekanizmasına sahip herbisitlerin kullanımı sonucu yabancı otlarda oluşan seçicilik ve direnç mekanizmalarındaki değişimler, bu alanlardaki yabancı otların farklı yoğunlukta bulunmasına neden olabilir (Tissut ve ark. 2006). Niğde patates dikim alanlarında en yaygın olarak bulunan yabanc1 otlardan Amaranthus spp., Chenopodium spp. ve Solanum nigrum triazin grubu etken maddeli herbisitlere direnç kazandıkları bir çok ülkede rapor edilmiştir (De Prado et al. 1993, Eleftherohorinos 2000). Bölgede giderek yaygınlığı artan bu yabanc1 otların önceki yıllara göre daha yoğun görülmelerinin nedeni bölgede patates yetiştiriciliğindeki yanlış uygulamalar olabilir. Bazı ilçelerde çok yoğun olan yabancı otların diğer ilçelerde yaygın olmamasının bir diğer nedeni, toprak ve iklimsel farklılıklar gibi ekolojik faktörlerden kaynaklanabilir.

Survey çalışmalarının sonucu olarak; Niğde patates dikim alanlarında yabancı otların giderek artan şekilde bir sorun olduğu belirlenmiştir. Bu yabancı otlardan Amaranthus hybridus, A. retroflexus, A. blitoides, Chenopodium album, Solanum 
nigrum, Cuscuta spp. ve Orabanche spp. artan bir şekilde Niğde patates dikim alanlarında ciddi verim kayıplarına neden olacaktır. Bitkisel üretimde başarıya ulaşabilmenin önemli unsurlarından biri olan planlı münavebenin sistemli olarak uygulanmamas1, yabanc1 ot mücadelesinde kullanılan ayn1 etken maddeli herbisitlerin sürekli kullanılması, yabancı otların zamanında kontrol edilememesi gibi durumlarda bölgede yabancı otlardan kaynaklı yüksek verim kayıpları meydana gelecektir.

\section{KAYNAKLAR}

Akça A. ve Işık D. 2016. Kayseri İli Şeker Pancarı (Beta vulgaris L.) ekiliş alanlarında bulunan yabancı otların tespiti. Bitki Koruma Bülteni, 56 (1), 115-124.

Aksoy U., Şekeroğlu A., Gökçe A. Çalışkan M. E., Serçe S., Çalışkan S., Özgen M., Kııınç Ö., Şen B., Özgen Ş, Taşkın H., Baloch F. S., Toktay H., Demirel U., Gökçe, A. F. ve Tındaş İ. 2014. TR71 Bölgesi'nde Tarım Sektörü Envanteri ve Öne Çıkan AR-GE Proje Önerileri. Doğuş Tarımsal AR-GE. Doğuş Grubu.

Anonim 2016a. http://faostat3.fao.org/home/E (siteye giriş tarihi: 05.10.2016)

Anonim 2016b. https://biruni.tuik.gov.tr/bitkiselapp/bitkisel.zul (siteye giriş tarihi: 05.10.2016)

Arslan B., Tunçtürk M., Eryiğit T., Ekin Z., ve Kaya A. R. 2002. Van-Erciş’ te bazı patates genotiplerinin verim ve verim komponentlerinin belirlenmesi. III. Ulusal Patates Kongresi, 23-27 Eylül 2002, Bornava İzmir, s. 381-391.

Baytop T., 1994. Türkçe Bitki Adları Sözlüğü - Dictionary of Turkish Plant Names, Türk Dil Kurumu Yayınları No: 578 - Turkish Language Foundation, Publication No: 578, Ankara.

Berksan Ö.F., 2002. Patates Tarımı (ed. Y. Şimşek), Kar Tarım, Ankara.

Bilgili A., Kadığlu İ. 2003. Tokat ili ve çevresinde Patates tarlalarında ortaya çıkan yabancı ot türlerinin yoğunlukları, dağılımları ve yöredeki yabancı ot florasının belirlenmesi, Gaziosmanpaşa Üniversitesi, Ziraat Fakültesi Dergisi, 20(2), 17-24.

Bora T. ve Karaca İ. 1970. Kültür bitkilerinde hastalığın ve zararın ölçülmesi. Ege Üniversitesi Yardımcı Ders Kitabı, Yayın No: 167, E.Ü. Mat., Bornova-İzmir.

Brush S. B. 1980. Potato taxonomies in Andean agriculture. In." Indigenous knowledge systems and development, (Eds. D.W. Brokensha, D.M. Warren and O. Werner), pp. 37-47. Univ Press of America, New York.

Carey J. B. Kells J. J. and Renner K. A. 1993. Common weed seedlings of Michigan. Department of Crop and Soil Sciences, Michigan State University Extension.

Çalışkan M. E. Onaran H., Arıoğlu H., 2010 "Overview of the Turkish potato sector: Challanges, achievements and expectations", Potato Research, 53, 255-266.

Davis P. H. 1965-1989. Flora of Turkey and The East Aegean Island. At the University Press, Edinburg, Vol. 1-10.

De Prado R. Dominguez C. and Tena M., 1993. Triazine resistance in biotypes of Solanum nigrum and four Amaranthus species found in Spain. Weed Research 33(1), 17-24. 
Niğde Yöresinde Patateste (Solanum tuberosum L.) Sorun Olan Yabancı Ot Türlerinin Yaygınlık ve Yoğunluklarının Belirlenmesi

Eberlein C.V., Petersom P. E., Guttieri M. J. and Stark J. C. 1997. Eonomics of cultivation weed control in potato. Weed Technology. 11(2), 257-264.

Eleftherohorinos I. G. Vasilakoglou I. B. and Dhima K.V. 2000. Metribuzin resistance in Amaranthus retroflexus and Chenopodium album found in Greece. Weed Science. 48, 69-74.

Gallandt E. R., Liebman M. Corson S, Porter G. A. and Ullrich S. D. 1998. Effects of Pest and Soil Management Systems on Weed Dynamics in Potato. Weed Science. 46(2), 238-248.

Hawkes J. G. 1993. The Potato: Evolution, biodiversity, and genetic resources. Smithsonian Institution Press, London, England, s :299.

Işık H. 1974. Patates Tarımı ve Gübrelemesi. Toprak ve Gübre Araş. Ens. Müd. Yayınları, Genel Yayın No:54, Çiftçi Yayınları No:1, Ankara

İlisulu, K., 1986. Nişasta ve Şeker Bitkileri ve Islahı. Ankara Üniv. Zir. Fak. Yayınları, 960, Ders Kitabı: 279, Ankara.

Kırsoy N. ve Nemli Y. 2001. Ödemiş İlçesi patates ekiliş alanlarında yabancı ot sorunun saptanması. Türkiye III. Herboloji Kongresi, Ankara, s:19.

Kubat A. Choroszewski P. and Pawinska M. 1996. Potato and weed problems in Poland. Proceedings of the Second International Weed Control Congress, Copenhagen, Denmark. Slagelse, 25-28 June, Denmark, Vol:1-4, 1037-1039.

Odum E. P. 1971. Fundamentals of ecology. W. B. Saunders Company, Philadelphia, London, Toronto, $574 \mathrm{p}$.

Özer Z. 1977. Patates Kültüründe Yabancı Otlar ve Kimyasal Mücadelesi. Atatürk Üniversitesi Ziraat Fakültesi Dergisi, Erzurum, 8, 95-106.

Özer Z. Önen H. Tursun N. ve Uygur F. N. 1999. Türkiye'nin Bazı Önemli Yabanc1 Otları (Tanımları ve Kimyasal Savaşları), Gaziosmanpaşa Üniversitesi, Ziraat Fakültesi yayınları No: 38 , No: 16.

Sönmez S. 1976. Bolu İlinde Patateslerde Yabancı ot Rekabeti vr Savaşı Üzerinde Araştırmalar. Dizer Konca Matbaası, İstanbul, s:104.

Tissut M. Delval J. M. and Ravanel P. 2006. Plantes, herbicides et désherbage ACTA, Paris, France, pp. 635.

Üstüner T. ve Güncan A. 2002. Niğde ve Yöresi Patates Tarlalarında Sorun Olan Yabancı Otların Yoğunluğu ve Önemi ile Topluluk Oluşturmaları Üzerine Araştırmalar Türkiye Herboloji Dergisi, 5(2), 30-42.

Zengin H. ve Güncan A. 1993. Erzurum ve yöresi patates dikim alanlarında sorun oluşturan yabancı otlar ve önemlilerinin topluluk oluşturma durumları üzerinde araştırmalar. Türkiye I. Herboloji Kongresi, 3-5 Şubat, Adana, s: 193-201.

Zimdahl R. L. 1976. Differantial Susceptibility of Potato Cultivars to Four Herbicides. American Potato Journal, 53, 211-219. 